\title{
JUAN BAUTISTA VÁZQUEZ “EL VIEJO” Y GASPAR NÚÑEZ DELGADO AL SERVICIO DEL VII DUQUE DE MEDINA SIDONIA (1575-1576)
}

\author{
FERNANDO CRUZ ISIDORO \\ Universidad de Sevilla
}

\begin{abstract}
Se documenta la labor de mecenazgo escultórico del VII duque de Medina Sidonia para su capilla de los palacios sevillano y sanluqueño, con el encargo de diversas obras a los escultores Juan Bautista Vázquez "el Viejo" y Gaspar Núñez Delgado, documentado este como oficial en su taller. Ambos realizan un nacimiento monumental y otras obras para las capillas.

Palabras clave: Mecenazgo nobiliario; Escultura; Juan Bautista Vázquez "el Viejo"; Gaspar Núñez Delgado; Imaginería; Alonso Pérez de Guzmán.
\end{abstract}

\section{JUAN BAUTISTA VÁZQUEZ “THE ELDER” \& GASPAR NÚÑEZ DELGADO IN THE SERVICE OF THE VII DUKE OF MEDINA SIDONIA (1575-1576)}

For the chapels in his palaces in Seville and San Lucar, the VII duke of Medina Sidonia ordered several works from the sculptors Juan Bautista Vázquez "the Elder" and Gaspar Núñez Delgado, documented as having been a skilled craftsman in Vázquez's studio. Both worked on a huge Nativity and other sculptures for the chapels.

Key words: Noble patronage; sculpture; Juan Bautista Vázquez "the Elder"; Gaspar Núñez Delgado; religious images; Alonso Pérez de Guzmán.

El mecenazgo arquitectónico y artístico del poderoso VII duque de Medina Sidonia don Alonso Pérez de Guzmán (1549-1615) ${ }^{1}$ resultó de gran calibre, por calidad y cantidad, a tenor de lo que venimos investigando. Gran parte del mismo se proyectó en Sanlúcar de Barrameda (Cádiz), capital de sus amplios estados y centro neurálgico de su intervención sobre el territorio, como ciudad marítima abierta al libre comercio atlántico, del Norte de África y Oriente Mediterráneo, donde se aprestaba la flota a Indias y que cerraba la entrada al navegable Guadalquivir en su acceso a una ciudad de realengo de la importancia de Sevilla, que detentaba el monopolio americano por su Casa de Contratación. Un mecenazgo fruto de la boyante economía mercantilista de la Casa, que se proyectó con esplendidez al resto de sus grandes villas dispersas por Andalucía Occidental, como Medina Sidonia, Trebujena, Vejer de la Frontera, Chiclana, Conil, Barbate, Niebla, Trigueros, Huelva, Almonte, Bollullos Par del Condado, Aljaraque, Coto de Doñana..., y más allá, a sus residencias y patronazgos. Indudablemente buscando un escudo ideológico ${ }^{2}$, que le hizo levantar veintidós edificios religiosos entre conventos, colegios, hospitales y su personal panteón, el sanluqueño Santuario de Ntra. Sra. de la Caridad, pero también hubo interés por la necesaria arquitectura militar para defender esos lugares (castillos de Sanlúcar, Niebla, Trebujena, Trigueros, Huelva y Conil), y por su calidad de Capitán General de la Costa de Andalucía y del Mar Océano, la defensa de esa zona del litoral con torres almenaras y artilladas ${ }^{3}$. A lo que añadir edificios fabriles como almadrabas para la pesca del atún y atarazanas, y la renovación de sus palacios urbanos, liderando novedosas formas en la arquitectura, escultura, pintura y artes suntuarias, pues supo contactar con artistas avanzados, nacionales y extranjeros, como italianos y flamencos, en Sevilla y Sanlúcar, puerta de las Indias y mercado cosmopolita.

En ese contexto recogemos el trabajo que efectuaron para el duque entre 1575 y 1576 dos maestros de primera fila en el panorama de la escuela escultórica manierista sevillana y bajo andaluza del último cuarto del siglo XVI, como fueron Juan Bautista Vázquez "el Viejo" y Gaspar Núñez Delgado, para las capillas de sus palacios sevillano y sanluqueño. Ambos artífices

\footnotetext{
1 Álvarez de Toledo, 1994.

2 Cruz Isidoro, 2005a: 427-434.

3 Cruz Isidoro, 2005b: 178-179.
} 
estaban inmersos en la renovación iniciada por el flamenco Roque de Balduque y continuada por diversos maestros toledanos, abulenses e italianos, puesta al servicio docente postridentino del culto mecenazgo de la aristocracia local y alto clero, de correcto gusto italianizante, de renovación naturalista, de tono popular, basada en la emotividad y el movimiento, que al final de la centuria se impuso por sus cofradías y fuerte devoción religiosa, y pronto devino en el primer barroco. Se documentan dos obras de Vázquez "el Viejo" y tres de Núñez Delgado, y otra realizada por ambos, que dimos a conocer hace unos años en un contexto local, pero que por su importancia y complementariedad es necesario adjuntar: un portalejo o mueble litúrgico a modo de retablo, con un Nacimiento o Belén, que de forma tan temprana como 1576 pone de evidencia el gusto español por este tipo iconográfico.

Vázquez "el Viejo" (ca.1510-1588) arribará a Sevilla sobre 1560, tras su etapa formativa abulense con los discípulos de Vasco de la Zarza, una posible estancia italiana y el bagaje de obras que dejó en Toledo y su arzobispado entre 1552 y 1560, por tanto, como maestro plenamente formado ${ }^{4}$. En la ciudad trabajará para su entorno geográfico e Hispanoamérica hasta su fallecimiento, y quizá el duque supo de su labor por el desaparecido retablo de la Sma. Trinidad, del extinto convento de San Francisco el Grande, junto al Ayuntamiento hispalense (1573), institución a la que don Alonso pertenecía. Escultor, ensamblador de retablos, pintor, decorador, proyectista de arquitecturas efímeras y grabador, mostrará un naturalismo idealizado de impronta manierista caracterizado por su alargamiento y suave romanismo miguelangelesco, que hará eclosionar la escuela sevillana, marcando como líder, tras la muerte de Balduque en 1561, las líneas básicas, de fuerte sabor clasicista, que luego hará triunfar Martínez Montañés ${ }^{5}$. En cuanto a Núñez Delgado ( $†$ ca.1606), posiblemente de origen castellano y que se creía discípulo de Jerónimo Hernández por su coetáneo Francisco Pacheco ${ }^{6}$, o quizás formado en el taller de Gaspar Becerra según Velázquez, que recoge Jusepe Martínez, comprobaremos cómo en verdad fue oficial del taller de Vázquez "el Viejo" con antelación a 1575, lo que demuestra su adiestramiento con ese escultor, al igual que Vázquez "el Mozo", Juan de Oviedo "el Viejo", Jerónimo Hernández, Diego de Velasco, Gaspar del Águila o Miguel Adán, entre otros escultores llegados de Castilla a su amparo. Documentado en Sevilla entre 1576 y 1606, constatamos cómo, al menos, llegó un año antes, representando una línea más vanguardista, temperamental, emotiva y gesticulante, que explotará la representación de tono naturalista dramática afín a la nueva sensibilidad popular, trazando de forma esquemática vestimentas de mayor movimiento con un ímpetu interior que explotará en la talla de los cabellos, anticipándose genialmente a la escuela barroca sevillana representada por Juan de Mesa, pero sin perder un ápice su asombrosa calidad técnica, tanto a la hora de labrar la madera, el dificultoso marfil o modelar el blando barro ${ }^{7}$.

El duque don Alonso les encargará en 1575 cinco imágenes y la restauración del retablo de la capilla de su monumental palacio sevillano ${ }^{8}$, tristemente desaparecido en la segunda mitad del siglo XIX, símbolo de su posición política en la ciudad. Ocupaba una gran manzana con plaza propia, la del Duque, en la collación de San Miguel, junto a la parroquia de ese nombre, y que conocemos gracias a las descripciones del historiador Félix González de León, de 1839 y 1844, y por dos planos de mediados del XVIII, sobre cuyo solar se asientan hoy unos grandes almacenes, El Corte Inglés. Era un viejo caserón de fisonomía mudéjar, fruto de la adición de varias

\footnotetext{
${ }^{4}$ Hernández díaz, 1951: 22-37. Estella Marcos, 1990.

5 Palomero PÁramo, 1983: 168-191; Recio Mir, 2009: 106-109; Hernández Díaz, 1989: 162-169; Gómez Piñol, 2007: 28-35.

6 PACheco, 1990: 385.

7 Palomero Páramo, 1983: 386-390; Luna Moreno, 2008-9: 381.

8 Álvarez de Toledo, 1994, t. I: 51.
} 
construcciones de fábrica de ladrillo, madera y teja, renovado al gusto renaciente por la madre del duque doña Leonor y por el propio don Alonso, que construyó una fachada unitaria con su crujía paralela, reformó buena parte del interior, y enriqueció su capilla con retablos e imágenes. Esta dependencia, de planta rectangular, se ubicaba en la "casa accesoria" o a la izquierda de la fachada, marcada con la leyenda: "Sala que corresponde a la Plazuela, cuya fábrica y su techo de bóveda, que están como en el ayre, demuestran ser oratorio", con un vano en un lado menor para "altar, en cuyo sitio está una columna con dos arcos".

El retablo, que sería de tipo tabernáculo y de planta lineal de un solo cuerpo tripartito, con amplia hornacina central y huecos laterales entre soportes, se restauró y completó de imaginería a principios de 1575, encargando el duque a Núñez Delgado, a través del criado ducal Juan Cordero, la talla de los "Santos Juanes, Bautista y Evangelista", de "un paso de Ntro. Sr. con la cruz a cuestas", y "reparar el dicho retablo de cosas", posiblemente para albergarlos. Que eran de bulto redondo y no relieves, parece desprenderse de la expresión "que hizo de talla, para el retablo de la capilla de mi casa", y de la nota marginal "a Gaspar Delgado, entallador, por tres ymágenes". Cobró el 18 de febrero 140 reales, por medio del criado Alonso de Montalbán, tras la orden ducal firmada en Sevilla. Del repaso de la policromía y dorado del retablo se encargó el pintor Juan Díaz, a quien se entregaron un día antes 25 ducados "por refrescar, dorar y adereçar el retablo de la capilla", así como por pintar dos artesones de lienzo grande para el enmaderamiento de los corredores y siete escudos de cuero dorado con las armas de los Guzmán para la Sala Grande ${ }^{10}$. Como el palacio desapareció, desconocemos el paradero de esas obras, aunque dada la magnanimidad del duque respecto a sus fundaciones religiosas, posiblemente las donase en vida a convento o hermandad de su patronazgo, o posteriormente lo hiciera alguno de sus herederos. Como en su catálogo de obras, que no es muy extenso, no figuran atribuciones de esa iconografía que pudiéramos simplemente confirmar con este documento, se dificulta su posible localización, quedando sólo la posibilidad de hallar similitud con alguna pieza anónima de esa cronología. Si analizamos su producción, este Bautista antecede en veinte años a otro para un retablo del convento sevillano de San Clemente, que contrató hacia 1605 junto con diversos relieves, que pasa por una de sus obras más avanzadas, de indudable fuerza barroca por su drama espiritual, reflejado en el rostro, y en el movimiento gesticulante, lleno de teatralidad. Y de igual forma, su innegable garra dramática y calidad material de impresionante estudio anatómico, se demuestra en su trabajo en barro cocido y policromado, con la magistral cabeza degollada del Bautista (firmada y fechada en 1591) del Museo de Bellas Artes de Sevilla, y en la serie de cabezas de Ecce-Homo, como la conservada en la Catedral hispalense ${ }^{11}$. Mayor interés, si cabe, tendría el contrato de un Nazareno de bulto redondo, para el que se utiliza el término "paso" aludiendo, según la definición n. ${ }^{\circ} 22$ que de ese término hace el Diccionario de la Real Academia Española, a la efigie o grupo que representa un suceso de la pasión de Cristo, aquí el portar su cruz camino del Calvario. No era tema muy tratado en esos momentos en la escuela escultórica hispalense, aunque se venía empleando en relieve desde el primer cuarto del siglo XVI en retablos de madera (mayor de la Catedral, del alemán Jorge Fernández, de hacia 1518-26) y alabastro (encargo de D. ${ }^{a}$ Leonor Manrique a Antonio María Aprile en 1525, hoy en el monasterio compostelano de San

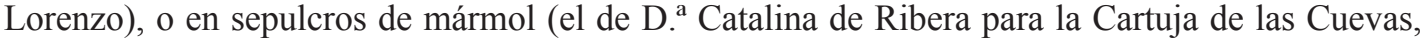
labrado por Pace Gazini en 1520), y difundirán a mediados de siglo Roque de Balduque (retablo mayor de Sta. M. ${ }^{a}$ de Cáceres, 1548-51; mayor de Sta. M. ${ }^{a}$ de la Asunción Coronada de Medina Sidonia, 1559-62), Isidro de Villoldo (mayor de la Cartuja de las Cuevas, 1553-55) y Vázquez “el

\footnotetext{
${ }^{9}$ Cruz Isidoro, 2006a: 247-262.

10 Archivo Ducal de Medina Sidonia, Sanlúcar de Barrameda (ADMS) leg. 2.641 fol. 2.

11 Palomero Páramo, 1983: 388; Pareja López, 1999: 318-328; Pareja López, 1991: 120-121; Luna Moreno, 2008-9: 379-394.
} 
Viejo" (mayor de Sta. M. a de la Asunción de Carmona, 1564-68). Más tardíos, ya de la segunda mitad del XVI, son los Nazarenos de talla completa, algunos de piedra y para hornacina (convento hispalense de la Encarnación, de mediados de la centuria), pero los más de madera (cedro, pino de Flandes o de Segura), algunos tallados por Gaspar del Águila (como el atribuido de la cofradía de la Soledad del convento del Carmen de Carmona, de 1573, actualmente en Mairena del Aljarafe); el desaparecido, y para vestir, de la cofradía del Rosario de Utrera, de 1578; el Cristo de las Fatigas, de 1587, de la iglesia hispalense de la Magdalena. Manieristas resultan el Nazareno de la Corona del Sagrario de la Catedral (último cuarto de siglo), en el momento de abrazar la cruz, popularizado por la pintura al fresco que Luis de Vargas realizara en 1563 en el retablo callejero perdido del Cristo de los Ahorcados, de la fachada del Sagrario a la calle Alemanes; Jesús del Perdón del convento de Santa María de Jesús, atribuido a Juan de Mesa (hacia 1615-20) y su documentado Gran Poder (1620) en la Basílica de su nombre; los nazarenos de Francisco de Ocampo (el que realizara para Carmona en 1607 o el sevillano de la Salud, de la parroquia de San Nicolás, que se le atribuye, sobre los años 1621-1622) $)^{12}$. El de Núñez Delgado ocuparía un lugar de privilegio en ese organigrama, entre el citado de piedra y el de la Corona, antecedente por su garra del célebre Gran Poder de Mesa, y en esta tesitura debemos hacer mención al Nazareno de esas fechas que actualmente se venera en la iglesia conventual de las Carmelitas descalzas de Sanlúcar de Barrameda, fundación de los duques de Medina Sidonia, a la que podría haber llegado por los avatares del tiempo la imagen que tratamos (fig. 1).

A Juan Bautista Vázquez "el Viejo", jefe del taller e igualmente calificado de entallador, se le encargó "la hechura y dorado de un Christo a la coluna y un San Pedro", sin explicitar si era para ese mismo oratorio, el del palacio sanluqueño o como dádiva para una institución religiosa o cofradía, cobrando 400 reales el 26 de marzo tras la preceptiva orden ducal firmada en Sevilla ${ }^{13}$, lo que implica también labores de policromía y estofado. Aunque se recogen por separado, podrían formar un conjunto iconográfico, el de la Lamentación o arrepentimiento de San Pedro, que en tal caso se dispondría arrodillado y compungido ante la visión del escarnio o flagelación de Cristo atado a la columna en el pretorio. A ese respecto, señalar cómo en la parroquia mayor de Ntra. Sra. de la O, de Sanlúcar, al lado del palacio ducal, hubo un conjunto formado, según nos cuenta el historiador Velázquez Gaztelu hacia 1758, por "el sagrado príncipe de los apóstoles, en actitud de su llanto y penitencia, después de sus negaciones, hincado de rodilla ante una devotísima imagen de Cristo,

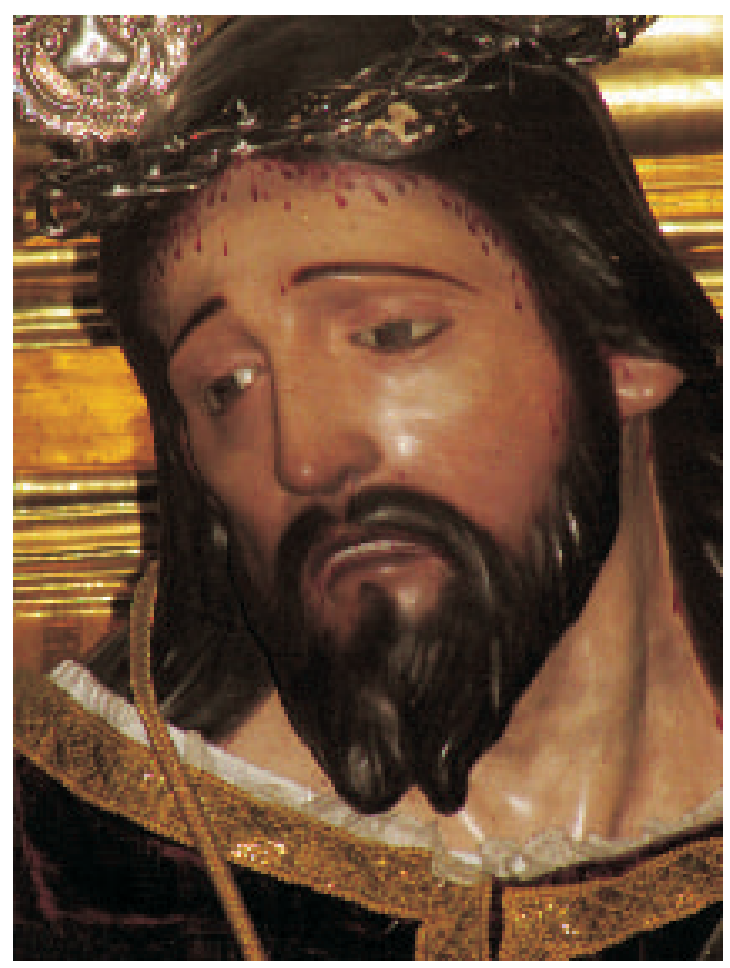

Fig. 1. Anónimo. Nazareno. Convento de Carmelitas Descalzas. Sanlúcar de Barrameda (Cádiz).

12 Roda Peña, 2002: 49-56, 63-68; Roda Peña, 2010: 73-101; Roda Peña, 2009: 212-213; Palomero Páramo, 1992: 338-339.

13 A.D.M.S. Sanlúcar de Barrameda, leg. 2.641, fol. 21 vto. 

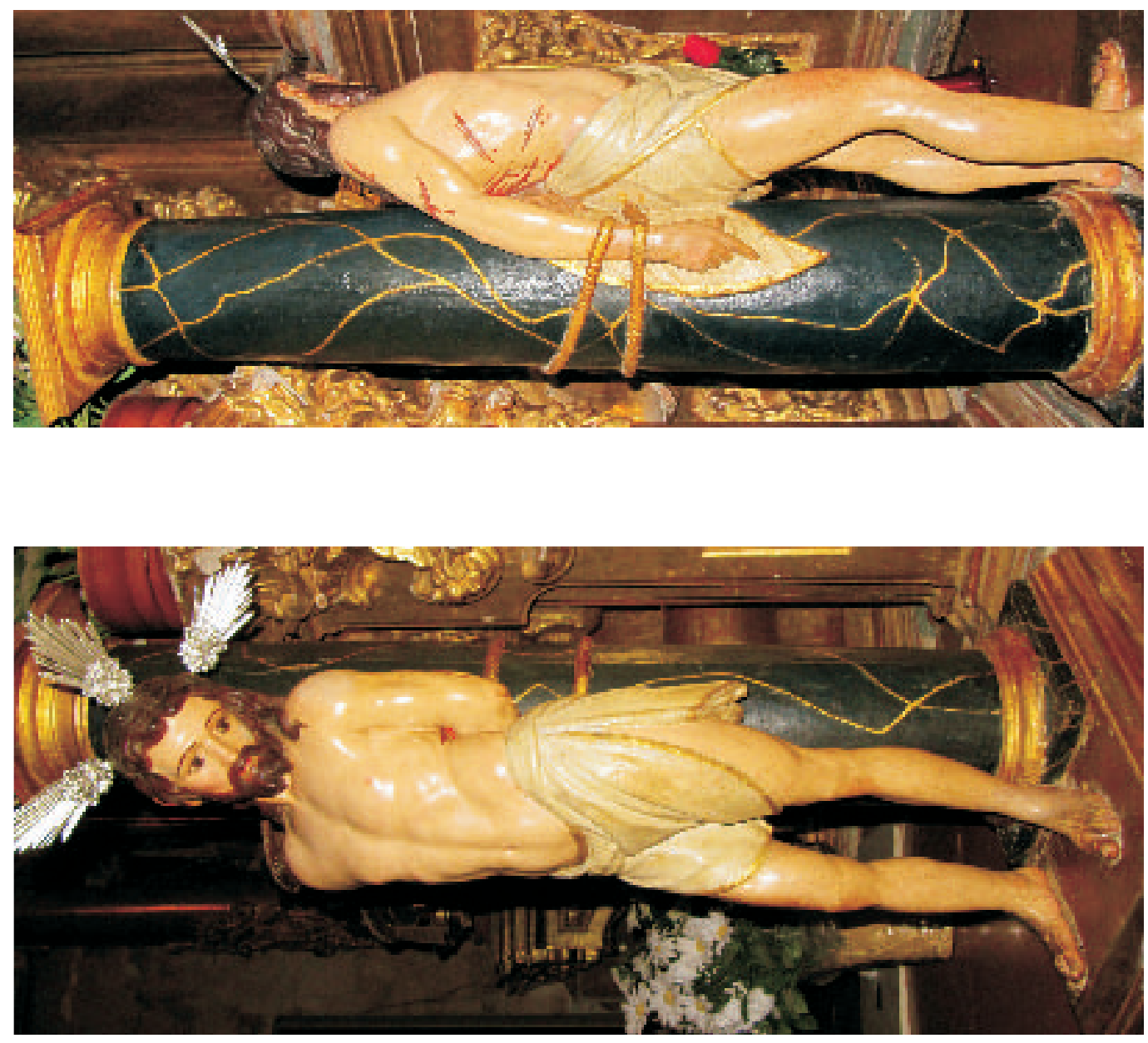

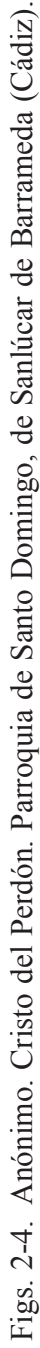

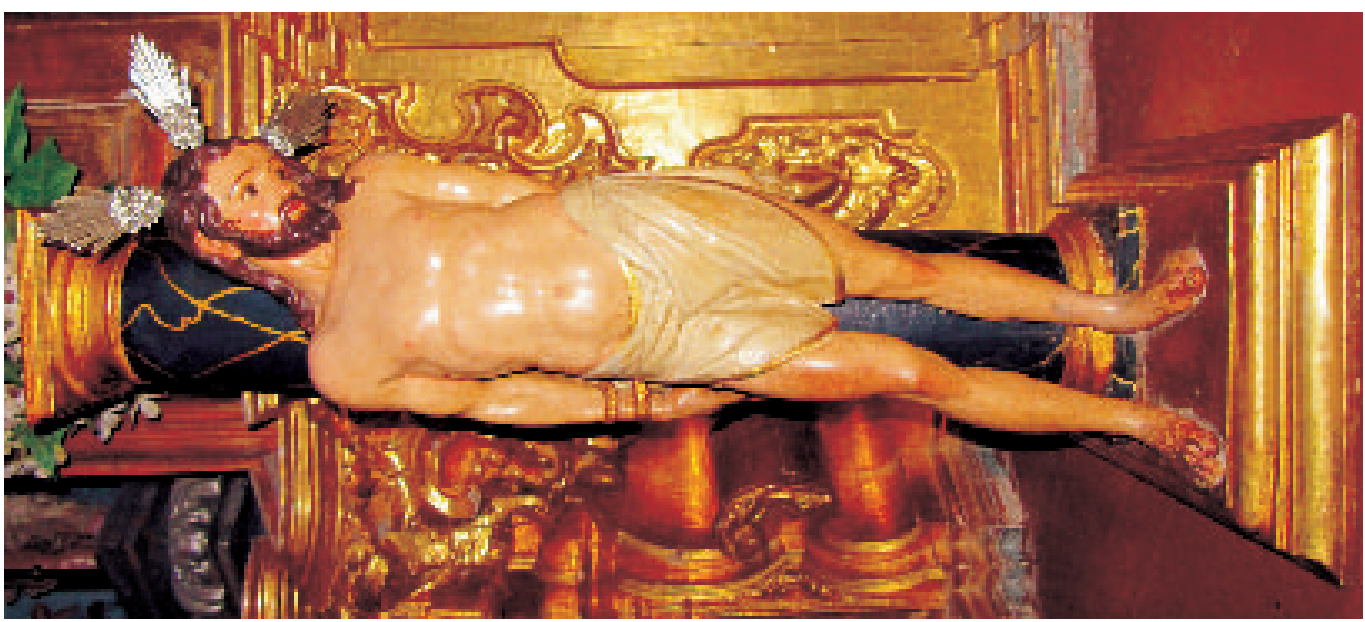

Arch. esp. arte, LXXXV, 339, JULIO-SEPTIEMBRE 2012, 265-292, ISSN: 0004-0428 
nuestro señor, amarrado a la columna". Nos dice que el grupo se encontraba en un espacio delimitado por rejas entre la puerta colateral de la Epístola y la capilla de Ntra. Sra. de la Antigua en el cuerpo de la torre ${ }^{14}$, sin detallar estilo ni tamaño, sólo su efecto dramático. No sería de extrañar que ambas piezas fuesen las de Vázquez "el Viejo", ya que esta parroquia aún conserva un riquísimo patrimonio donado por la Casa ducal. De estilo manierista y de esos años de 1570 es el Cristo del Perdón, atado a la columna, que se conserva en la iglesia sanluqueña de Santo Domingo (figs. 2-4) antaño convento dominico patronado por los duques, que aunque muestra unas formas similares al relieve del Atado a la columna que Vázquez "el Viejo" realizara para el retablo mayor de la iglesia de Sta. María de Carmona, dispuesto en el tercer cuerpo, en la entrecalle izquierda, no aca-
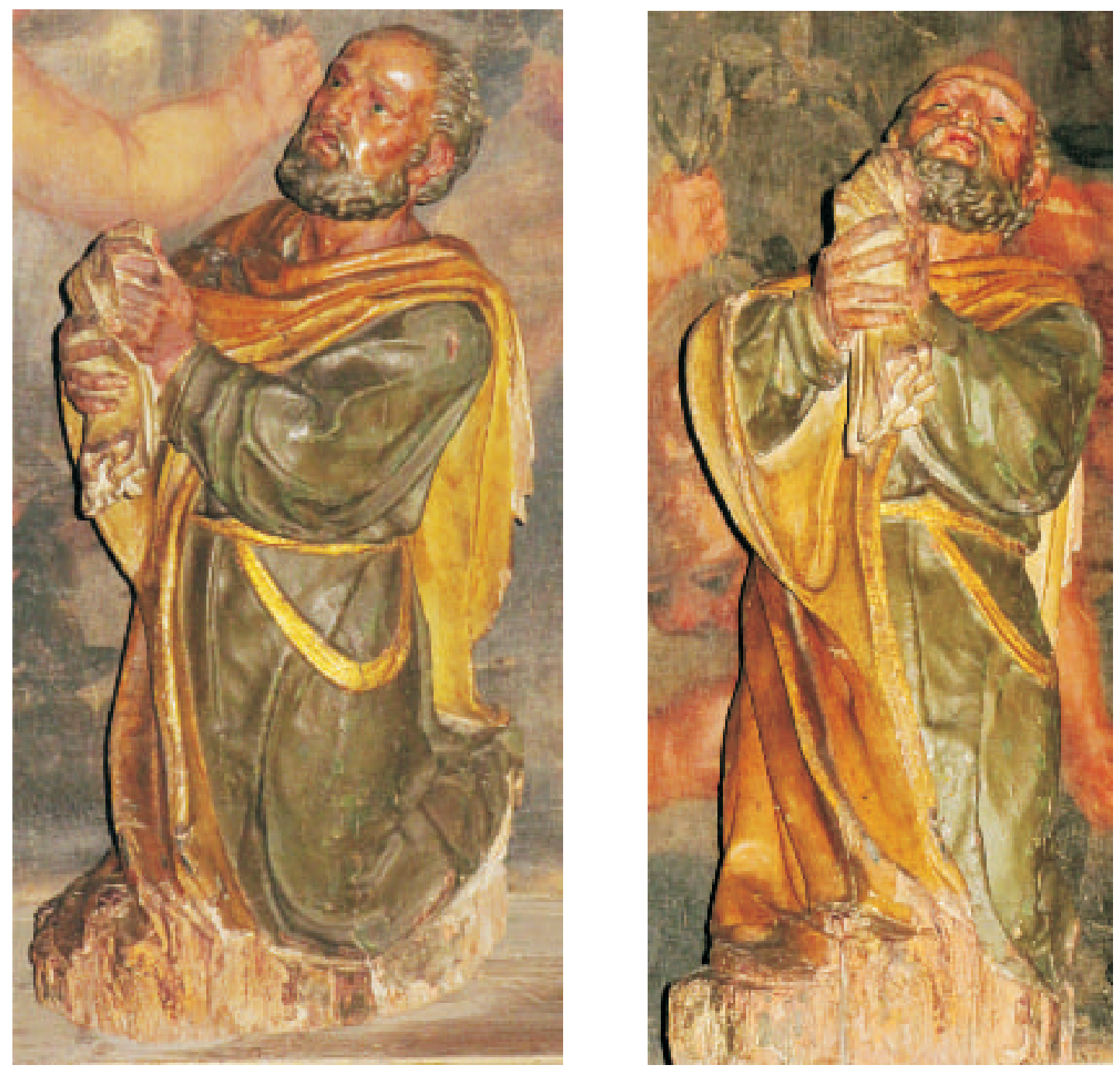

Figs. 5-6. ¿Juan Bautista Vázquez “el Viejo”? San Pedro arrodillado. Basílica de Ntra. Sra. de la Caridad, de Sanlúcar de Barrameda (Cádiz).

14 Velázquez Gaztelu, 1995: 85. 
ba de corresponder a su estilo, pues nos parece de inferior calidad, a pesar de mostrar de igual forma la columna alta, anterior a Trento, la disposición de Jesús con la espalda pegada a ella y las manos hacia atrás, postura imposible para recibir el castigo pero necesaria para mostrarlo al fiel, y cierta semejanza anatómica, tanto en el tratamiento alargado de su cuerpo desnudo, como en el del paño de pureza, que adopta forma en $\mathrm{V}$ para mostrar el abdomen. Hasta hace unos años, en una hornacina del retablo mayor del Santuario de Ntra. Sra. de la Caridad, panteón de don Alonso, se disponía un San Pedro arrodillado que, tras la reciente restauración de la máquina, fue retirado por su mal estado de conservación, conservándose en la actualidad en su interesante retablo-relicario. Una somera limpieza de la imagen (retirada del polvo acumulado), nos permite vincular la talla al estilo y cronología en la que nos movemos, similar al San Pedro del relieve de la Asunción de la Virgen del retablo mayor de Sta. María de Carmona y, por tanto, vincularlo a la gubia de Vázquez "el Viejo". Arrodillado, con túnica verde y manto terciado dorado, con dinámicos pliegues diagonales, aprieta nerviosamente las manos juntas en oración sobre una esquina del manto, alzando su compungido rostro al Maestro para solicitarle perdón. Destaca la talla del rostro, con su habitual fisonomía, de prolija barba (figs. 5-6).

El VII duque debió quedar satisfecho con esas esculturas e intervenciones, pues un año más tarde, en 1576, les encargó para la capilla de la tribuna de su palacio sanluqueño un portalejo o Nacimiento en forma de Belén monumental de figuras exentas de gran tamaño, lamentablemente perdido, tallado entre marzo y noviembre por 112.200 maravedíes. Fue montado por Gaspar Núñez Delgado, que lo transportó en barco por el Guadalquivir desde Sevilla, y sabemos de su fisonomía por una descripción de octubre de 1588: "un Nacimiento de madera de talla, con un poste dorado por debaxo, con quatro postes dorados que lo sostienen; tiene una urna dorada con un Niño Jesús encima della, y a la mano derecha está la Virgen María, Nuestra Señora, y a la izquierda San Josep y un ángel con un paño de manos, que parece que quiere cubrir el Niño Jesús. Y junto a ésta está un buey y una mula, tiene también quatro pastores debajo del portal y una pastora entre ellos, con gaytas, y fuera del portalejo está un pastor en el suelo, tendido, guardando siete ovejas, y un perro, que las guarda junto a una montaña, y dos ángeles colgados de este dicho, y una sierra, todas estas figura son doradas y de colores" $" 15$.

\section{BIBLIOGRAFÍA}

Álvarez de Toledo, Luisa Isabel: Alonso Pérez de Guzmán. General de la Invencible, Libros $1 .^{\circ}$ y $2 .^{\circ}$, Cádiz, 1994.

Cruz Isidoro, Fernando: "Un cuadro de altar de trasfondo ideológico: "la Genealogía de los Guzmanes", del pintor barroco Francisco Juanete (1612)", Archivo Español de Arte n. ${ }^{\circ} 312$, Madrid, 2005a, pp. $427-$ 434.

Cruz Isidoro, Fernando: "El mecenazgo arquitectónico de la Casa ducal de Medina Sidonia en su estado territorial entre 1559 y 1633", Laboratorio de Arte n. ${ }^{\circ}$ 18, Sevilla, 2005b, pp. 178-179.

Cruz Isidoro, Fernando: "El palacio sevillano de los Guzmanes según dos planos de mediados del siglo XVIII", Laboratorio de Arte n. ${ }^{\circ}$ 19, Sevilla, 2006a, pp. 247-262.

Cruz Isidoro, Fernando: El Belén de los Guzmanes de 1576: un portalejo de Juan Bautista Vázquez "el Viejo” y Gaspar Núñez Delgado, Sanlúcar de Barrameda, 2006b.

Estella Marcos, Margarita: Juan Bautista Vázquez el Viejo en Castilla y América. Nicolás de Vergara, su colaborador, Madrid, 1990.

Gómez Piñol, Emilio: "Las atribuciones en el estudio de la escultura: nuevas propuestas y reflexiones sobre obras de la escuela sevillana de los siglos XVI y XVII", Nuevas perspectivas críticas sobre historia de la escultura sevillana, Sevilla, 2007, pp. 28-35.

15 Cruz Isidoro, 2006b. A.D.M.S. Sanlúcar de Barrameda, leg. 2.625; 2.628; 2.641 fols. 329 vto., 333 y vto.; 2.670 fol. 183 ; leg. 2.757. 
Hernández Díaz, José: Imaginería hispalense del Bajo Renacimiento, Sevilla, 1951, pp. 22-37.

Hernández Díaz, José: “Escultura”, El Arte del Renacimiento, escultura-pintura y artes decorativas, Sevilla, 1989, pp. 162-169.

Luna Moreno, Luis: “Gaspar Núñez Delgado y la escultura de barro cocido en Sevilla”, Laboratorio de Arte n. ${ }^{\circ} 21$, Sevilla, 2008-9, pp. 381.

Pacheco, Francisco: Arte de la Pintura, Madrid, 1990, p. 385.

Palomero Páramo, Jesús M.: El retablo sevillano del Renacimiento, Sevilla, 1983, pp. 168-191.

Pareja López, Enrique: "Escultura”, Museo de Bellas Artes de Sevilla, Sevilla, 1991, pp. 120-121.

Pareja López, Enrique: “Obras maestras del arte”, Real Monasterio de San Clemente. Historia, tradición y liturgia, Córdoba, 1999, pp. 318-328.

Recio Mir, Álvaro: "La versatilidad del Renacimiento: variedad material, icónica, tipológica y funcional", El Retablo Sevillano, desde sus orígenes a la actualidad, Sevilla, 2009, pp. 106-109.

Roda Peña, José: “El Nazareno en la Escultura sevillana”, Nazarenos de Sevilla, t. I, Sevilla, 1997, pp. 4956, 63-68.

Roda Peña, José: “Jesús del Perdón”, La Ciudad Oculta. El Universo de las clausuras de Sevilla, Sevilla, 2009, pp. 212-213.

Roda Peña, José: "El Nazareno de las Fatigas y su capilla en la parroquia de Santa María Magdalena de Sevilla", Laboratorio de Arte n. ${ }^{\circ} 22$, Sevilla, 2010, pp. 73-101.

Velázquez Gaztelu, Juan Pedro: Fundaciones de todas las iglesias, conventos y ermitas de la muy noble y muy leal ciudad de Sanlúcar de Barrameda. Año de 1758. Sanlúcar de Barrameda, 1995, p. 85. 